\title{
PARA UNA NUEVA FILOSOFÍA DE LA HISTORIA ${ }^{1}$
}

\section{FOR A NEW PHILOSOPHY OF HISTORY}

\author{
JOHANNES ROHBECK* \\ Technischen Universität Dresden
}

Resumen: El objetivo de este artículo es presentar una filosofía de la historia que no se limite a los análisis de las representaciones de acontecimientos y procesos pasados, sino que se oriente, más bien, a las acciones del presente en relación al futuro. La filosofía de la historia queda vinculada a la ética del futuro en la medida que en ella se expresa una intención práctica. De este programa se deriva que la ética del futuro tendrá que abrirse a las reflexiones de la filosofía de la historia e incluir en su propia fundamentación determinados juicios de la estructura y la función de la conciencia histórica. Para la Filosofía de la Historia esto tiene como consecuencia que habrá de implicarse en la solución de problemas actuales con perspectiva de futuro, así como coligarse con la filosofía práctica. Por eso la llamo filosofía práctica de la historia.

Palabras clave: futuro, legado, historia, justicia, generación.

AвSTRACT: The central idea of this paper is that our contemporary historical awareness which is increasingly turning towards future is accessible to philosophical reflection.

1 Traducción del alemán de Manuel Orozco Pérez (Universidad Carlos III de Madrid)

* Professor für Praktische Philosophie und Didaktik der Philosophie, Institut für Philosophie der Technischen Universität Dresden. E-mail: Johannes.Rohbeck@tu-dresden.de 
This raises the question whether we need a new Philosophy of History which refers less to past but primarily aims at present and future problems. If thereby a moral responsibility for future generations is addressed Philosophy of History goes hand in hand with Future Ethics. By means of this programme I expressly follow the Philosophy of History since the European Enlightenment. Whereas Historicism is committed to the past and the so called Posthistoire remains restricted to the present, within the classical Philosophy of History representations of the historical process serve as justification for corresponding future expectations. This entails an ethical perspective since the progress in history is not simply predicted but is more or less explicitly declared as desirable tendency which is associated to the moral and political plea to commit oneself to a realisation of these positive development.

KEYwORDs: future, legacy, history, justice, generation

En el canon de las disciplinas filosóficas la Filosofía de la Historia sólo juega un papel marginal. Y cuando se habla de ella, se hace en el marco de problemas metodológicos de la investigación y representación histórica. De ahí que tenga que describir cómo los historiadores juzgan y dan constancia de sus fuentes para clarificar qué es lo que hay que entender por hechos históricos. Aquí se pregunta con qué se vincula la ciencia de la historia y qué función cumplen las representaciones de lo histórico. Si el historiador no reproduce sin más los acontecimientos concretos, se trata entonces de interpretaciones de la historia. Aquí entra en escena, junto a la comprensión de las acciones humanas, la explicación de los procesos históricos, especialmente teniendo en cuenta que la contraposición tradicional entre estos dos modelos de interpretación puede, entretanto, considerarse como superada. Existe asimismo un consenso en que la representación histórica es esencialmente una narración que se puede investigar de forma narratológica. Como consecuencia del giro lingüistico, el interés se concentra en el terreno del análisis del lenguaje y de la teoría del discurso. Complementariamente, existen investigaciones sobre memoria colectiva y cultura de la memoria.

Mas en tal balance de la situación apenas se puede disimular que se trata de una reducción de la filosofía de la historia. Algunos hablan de "niveles de pérdida" o "funciones residuales". De este modo, al menos, se mantiene vivo el recuerdo de que originalmente la Filosofía de la Historia se ha propuesto tareas duraderas. Con esto me refiero a una disciplina filosófica que se ha ido

1 Marquard (1973), 23 y ss. - Nagl-Docekal (1996), 7 y ss. han reconstruido estos niveles de pérdida de forma detallada; cf. Lübbe (1993). 
constituyendo durante la ilustración europea, de manera bastante precisa en torno a la mitad del siglo XVIII y que ha encontrado partidarios hasta nuestros días. Si se quiere expresar terminológicamente la diferencia entre el modo de pensamiento antiguo y el moderno, se puede hablar de la formación histórica de la filosofía de la historia (Geschichtsphilosophie) a la cual se contrapone la variante actual de una Filosofía de la Historia (Philosophie der Geschichte) susceptible de ser reducida a lo metódico².

Es ciertamente indiscutible que el análisis moderno del discurso ha conducido a importantes conocimientos metodológicos; sin embargo, no se deben ocultar las pérdidas sufridas en el camino; y es que la clásica filosofía de la historia se caracteriza esencialmente por reflejar los contenidos de lo histórico. De esos contenidos forman parte temas como la relación entre naturaleza e historia, ilustración y modernidad, historia universal y globalización o justicia global e intergeneracional. De este modo, surgen las preguntas por la relación entre tiempos y espacios históricos, así como por las formas progresivas de la historia como regresión, estancamiento o progreso con las correspondientes imágenes de la historia (ciclo, ondulación o flecha ascendente). En este contexto, lo esencial es la perspectiva de futuro en su intención práctica.

Siguiendo esta caracterización, se deriva la clasificación en una filosofía de la historia material, que tematiza los contenidos mencionados, y una Filosofía de la Historia formal, orientada a problemas metodológicos. Bajo este presupuesto, sería perfectamente posible pensar que ambos modelos se den simultáneamente o que se complementen de forma recíproca, como ya el modelo clásico -por ejemplo, Kant- supo articular entre lo contenido y lo metódico. Si se toma en serio esta relación, que en realidad es de sentido común, la estricta separación entre una variante formal y una material tiene poco sentido. Parecería entonces más oportuno aspirar a una Filosofía de la Historia material que aborde, al mismo tiempo, la reflexión metódica.

Siempre y cuando la filosofía de la historia así ampliada remita no tanto a los acontecimientos del pasado, sino que se oriente, más bien, a las acciones del

2 En este contexto cf. Baumgartner (1996), 151 y ss. - Detrás de esta reducción se encuentra la crítica habitual a la filosofía de la historia, crítica que he resumido recientemente de manera sistemática: Johannes Rohbeck, "Rettende Kritik der Geschichtsphilosophie. Immanuel Kant im europäischen Kontext", en: Elbe, Ingo / Ellmers, Sven / Hesse, Christoph / Schmieder, Falko / Wallat, Hendrik (eds.), Zeitschrift für kritische Sozialtheorie und Philosophie. Vol. 1, número 2, 350-376; véase también: Johannes Rohbeck (2010), 54 y ss. 
presente en relación al futuro, se presentará el problema de en qué medida el futuro representa un espacio de proyección que, sin más, se pueda comprender como historia. Me permito aquí recordar la circunstancia de que el concepto moderno de futuro surgió en el contexto del pensamiento de la filosofía de la historia del siglo XVIII ${ }^{3}$. Del historicismo del siglo XIX hay que aprender que el futuro, así como el pasado, no se puede deducir de manera inmediata. Por el contrario, es necesario reflexionar sobre el punto de vista propio y sobre la remisión particular al futuro para conseguir una relación reflexiva con él. De este modo, se puede describir como círculo hermenéutico la relación del presente no sólo con el pasado, sino también con el futuro. Proyectamos nuestras experiencias del presente en el pasado y en el futuro, del mismo modo que las representaciones del futuro y del pasado influyen en nuestra orientación en el presente. También la dicotomía espacio de experiencia y horizonte de expectativa de Reinhart Koselleck posee este trasfondo hermenéutico ${ }^{4}$.

Si, además, se alude a la responsabilidad moral para con las generaciones futuras, la filosofía de la historia queda vinculada a la ética del futuro, sin ser, naturalmente, absorbida por ella. De este programa se deriva que la ética del futuro tendrá que abrirse a las reflexiones de la filosofía de la historia e incluir en su propia fundamentación determinados juicios de la estructura y la función de la conciencia histórica. Para la filosofía de la historia esto tiene como consecuencia que habrá de implicarse en la solución de problemas actuales con perspectiva de futuro, así como coligarse con la filosofía práctica. Por eso la llamo filosofía práctica de la historia.

En un principio, defino historia de un modo general, en tanto que consecuencia temporal de generaciones que han sido transmitidas mediante el legado. Dado que el legado posibilita un planteamiento polifacético, se desoculta el horizonte para un cambio cultural y un proceso abierto. A esto, vinculo el principio ético de la autonomía, principio que hay que garantizar mediante medidas cautelares. Para estructurar los periodos de este tipo de acciones, utilizo el concepto de plazo, el cual permite graduar de un modo espacial y temporal el alcance de la responsabilidad moral según los distintos campos de acción. Introduciendo en escena la dimensión global, se plantea la pregunta cómo se puede justificar la exigencia tan extendida de que se recuperen y desarrollen los pueblos hasta ahora

${ }^{3}$ Hölscher (1999), 9 y ss.

${ }^{4}$ Koselleck (1979), 349 y ss., especialmente 356; del mismo autor (2003), 249; cf. Rüsen (1994), 6 y ss. 
discriminados. A este respecto, analizo la estructura histórica de este desarrollo y formulo, al mismo tiempo, una norma propia de la filosofía de la historia, norma que entiendo como un deseo de mejora.

\section{Generación y legado}

Considerando la responsabilidad para con las generaciones futuras desde el punto de vista de una filosofía de la historia, es necesario cuestionar la relación histórica entre las sucesivas generaciones. En la ética del futuro más actual se han implantado diferentes modelos para hacer imaginable la relación de la humanidad actual con la del futuro. El amparo familiar cumple la función de modelo elemental, teniendo como principal ventaja la cercanía del entorno vital; sin embargo, este amparo se da únicamente dentro de los límites de las tres generaciones coexistentes ${ }^{5}$. Conocidos son también el modelo del diálogo entre las generaciones presentes y futuras ${ }^{6} \mathrm{y}$ el constructo del pacto intergeneracional. Ambos modelos tienen, por su parte, la prioridad de la prolongación hasta el futuro lejano, pero son ficticios y abstractos. El problema reside entonces en encontrar un modelo que sea menos ficticio y, al mismo tiempo, dilatable temporalmente.

Como propuesta planteo el modelo de la herencia intergeneracional o del legado. Esto sobrepasa el límite temporal del amparo familiar y es, a su vez, más realista que las construcciones de un diálogo o contrato ficticio. Además, este modelo permite dejar suficientemente abierto el trato futuro con lo legado.

$\mathrm{Al}$ igual que el concepto de generación, el modelo de legado tiene su origen en la filosofía de la historia del siglo XVIII ${ }^{8}$. Ahí se cruzan generación y herencia. Siempre y cuando el concepto de generación sea comprendido no sólo de

5 Jonas apoyándose en el concepto de cuidado (Sorge) de Heidegger: (1979), 84, 197 y ss.; cf. Laslett (1992), 24 y ss.; Höffe (1993), 182; Unnerstall (1999), 66; Leist (2005), 459 y ss.; Birnbacher (2008), 33; Böhler (2009), 29.

6 Gethmann (1993), 12; Ott, Döring (2008), 92; Böhler (2009), 28 y ss., 84 y ss.

7 Rawls (1979), 319 y ss.; véase también Laslett (1992), 24 y ss.; Höffe (1993), 183; Veith (2006), 127 y ss.; Heubach (2008), 136 y ss.; Ott, Döring (2008), 96 y ss.; Tremmel (2012), 221 y ss.

8 Ya Turgot definía la historia como transmisión de un tesoro cultural, "que pasa una generación a la siguiente como una herencia", Anne Robert Jacques Turgot, Über die Fortschritte des menschlichen Geistes, Frankfurt/M. 1990, 140. Cf. Rohbeck (2010), 126 y ss.; del mismo autor (2013), 130 y ss. 
forma sincrónica ${ }^{9}$, sino también y muy especialmente de modo diacrónico, el concepto de legado podrá caracterizar la conexión en las sucesivas generaciones. La generación es así un grupo social que recibe un legado de un grupo que le precede. De manera que, por regla general, tampoco hay legado alguno que no sea transmitido de una generación a la siguiente. El legado constituye un proceso cultural en tanto que convierte en herederas a las generaciones futuras y en testadoras a las generaciones presentes. Así, cada generación a su manera asume una responsabilidad particular para con lo legado.

En la relación de las generaciones juega un papel destacado la herencia reglada jurídicamente entre los sucesivos grupos de individuos. Sin embargo, en el centro de la ética del futuro el legado colectivo ${ }^{10}$ se encuentra vinculado a la herencia entre las generaciones, y que hay que entender como consecuencia histórica de grupos poblacionales. A éstos pertenecen grupos étnicos o regionales, pueblos o Estados nacionales, culminando en la sociedad mundial, de modo que se pueda distinguir entre un legado nacional y otro global. De esta forma se puede especificar el contenido del legado intergeneracional.

A este legado pertenecen, primeramente, las riquezas económicas, los bienes materiales, como por ejemplo las instalaciones y edificios públicos y los sistemas de transporte y comunicación. Asimismo, existe el legado cultural en forma del saber y poder transmitidos, tales como la educación (Bildung), el lenguaje, el arte y la religión. El legado social consiste en instituciones sociales o bien en diferentes formas de los sistemas sociales de reglas ${ }^{11}$. Desde la crisis ecológica, el medio natural se concibe asimismo como un legado que será transmitido a las generaciones siguientes ${ }^{12}$. Sin embargo, a menudo este legado es poco positivo.

9 El concepto sincrónico de generaciones prevalece desde el siglo XX, como por ejemplo en Karl Mannheim, "Das Problem der Generation”, en: Wissenssoziologie, Berlin/Neuwied 1964, 509 y ff.

10 En el informe Brundtland se habla de "la administración del legado común", Hauff (1987), 259 y ss.; cf. Jonas (1979), 72 y ss.; Meyer (2005), 135 y ss.

${ }^{11}$ En este contexto se usa frecuentemente el concepto de capital. Aunque se trata de un concepto amplio de capital que integra componentes sociales y culturales, existe, sin embargo, el peligro de una economización de todos los ámbitos de la vida. Esta explosividad se muestra especialmente en el concepto de capital social y en los debates con él relacionados: Putnam (2001), 19, 24; cf. Kopfmüller (entre otros) (2001), 68 y ss.; Ott, Döring (2008), 145; Tremmel (2012), 119 y ss. - En el lado opuesto se encuentra el uso crítico del concepto de capital llevado a cabo por Bourdieu (1983), 183, 190 y ss.

12 Véase el "Convenio sobre la protección el patrimonio cultural y natural" de la UNESCO del ańo 1972. - Weikard (1999), 130 y ss.; Heubach (2008), 61 y ss. 
Entre los ejemplos negativos se encuentran la enorme deuda de muchos Estados, la pobreza extendida a nivel mundial, el medio ambiente contaminado, la escasez de recursos naturales y el cambio climático. En tales casos lo que se hereda son males de carácter colectivo.

Para analizar la estructura de esta forma de transmisión sirve una vez más el contraste con los modelos de amparo, diálogo y contrato; modelos que tienen ciertamente su propio "objeto", pero que, a pesar de ello, consisten fundamentalmente en una relación bilateral. De esta forma, el amparo se basa en la interacción directa entre dos personas coexistentes. El modelo del legado, por el contrario, no implica una comunicación inmediata, sino que representa esencialmente la forma de una mediación. Con el legado aparece, entre las generaciones sucesivas, un tercero real que viene dado por la transmisión y que constituye una relación trilátera que no se deja reducir a dos partes. Se trata en este punto de bienes que existen independientemente del testador y del heredero, y son transmitidos como entidades autónomas. De ahí resulta una ambivalencia particular.

Por un lado, los bienes legados nos son objetos neutrales, sino que encarnan determinadas formas de uso y, con ello, también costumbres de vida. Por su carácter material, representan ciertas formas de práctica y toma de posición ante valores concretos. Las centrales nucleares transmiten una actitud diferente hacia el medio ambiente que las formas alternativas de abastecimiento energético. Una sociedad orientada al automóvil supone un estilo de vida muy diferente al de una ciudad con un desarrollado sistema de medios de transporte público. Con un legado como éste, los testadores crean no sólo las condiciones de mundos de vida futuros, sino que influyen también en las preferencias de las generaciones posteriores.

Por otro lado, a las generaciones posteriores se les da la libertad, dentro de ciertos límites, de hacer el uso que crean conveniente de lo heredado. El legado cumple la función de un medio objetual que puede usarse de diferentes formas. Para el usuario esto supone restricciones, así como un buen potencial. Por eso, este modelo permite hacer pensable y deseable la libre disponibilidad de lo heredado. Abre un horizonte de posibilidades reales que puede ser aprovechado por los descendientes según su propio parecer. El legado se convierte así en una categoría ética. Para las personas que viven en el presente esto supone el impe- 
rativo de dejar un "buen" legado y proporcionar libertad de movimientos para una apropiación autónoma.

\section{La apertura condicionada de la historia}

La función ambivalente del legado se puede ahora generalizar con vistas a la historia. Partiendo de un uso lo más flexible posible del legado, se ocultaría la idea de un proceso histórico abierto principal. Bajo el presupuesto de que la autonomía es, por lo general, deseable, se puede deducir de ahí el mandamiento moral según el cual a las futuras generaciones no les deberíamos garantizar únicamente un cambio de su forma de vida, sino que, mediante medidas concretas, les deberíamos dar la libertad de cambiarla. La posibilitación del cambio cultural hay que formularla como una obligación que reconozca el derecho de autodeterminación de cada generación. Precisamente porque no podemos conocer los deseos de las generaciones futuras estamos obligados a crear las condiciones para una libertad de elección que sea lo más amplia posible.

Para tomar precauciones ante tales condiciones de vida es necesario limitar, en parte, el carácter abierto de la historia. En el futuro no debe estar todo permitido, si ello conlleva determinados peligros. Esto conduciría a un liberalismo radical, con lo que toda responsabilidad a largo plazo resultaría superficial. En este caso, incluso se contradirían los principios apertura de la historia y de responsabilidad para las generaciones futuras. La limitación exigida está vinculada a un medio ambiente con calidad de vida, al mantenimiento de los recursos naturales, a una infraestructura intacta y a una Hacienda pública que sea adecuada. Por eso, es necesario establecer una nueva relación entre la apertura y la uniformidad de la historia.

Por un lado, el principio de apertura permite proyectar hacia el futuro el desarrollo presente de la civilización científico-técnica ${ }^{13}$. La experiencia histórica

${ }^{13}$ Las éticas tradicionales del futuro, en el fondo, continúan el proceso histórico actual, suponiendo ciertamente que las futuras generaciones desarrollarán nuevas tecnologías, pero tendrán, en última instancia, las mismas necesidades e intereses, de manera que se pueda calcular en cualquier momento la suma total de utilidad de bienes y de deseos de felicidad. - Birnbacher (1988) 101 y ss.; crítico de esta posición: Höffe (1993), 184; Weikard (1999), 10; Leist (2005), p. 470 y ss.; Sturma (2006) 230. - Igualmente problemático es establecer el "bienestar" de generaciones futuras según los indicadores objetivos del Human Development Index (HDI; Tremmel (2012), 153,193 y ss. 
de que en las sociedades modernas se han dado cambios históricos alimenta la esperanza de que, de igual manera, en el futuro habrá un cambio cultural. Esto supone un comportamiento práctico para ocuparse de las condiciones de posibilidad de un desarrollo de este tipo. Así, por ejemplo, deberíamos dejar como legado no sólo determinados sistemas de comunicación, sino, además, la libertad de revisar sistemas concretos y de cómo definir el valor de la "movilidad". Asimismo, proyectos de cooperación intergeneracional, como por ejemplo la navegación espacial, deberían ponerse en práctica de un modo flexible, de forma que las generaciones siguientes tengan la posibilidad de cambiar los planes correspondientes o, incluso, de anularlos.

En referencia a la teoría de la doble contingencia de Niklas Luhmann, me gustaría hablar de una triple contingencia. La doble contingencia surge de la interacción simultánea de personas que comunican ${ }^{14}$. Consiste en la indeterminación de interpretaciones recíprocas, cuando una persona no puede estar segura si la otra la comprende correctamente. Esta contingencia afecta al presente dentro del cual las contingencias se negocian y se renuncia a las decisiones por o contra una política precavida. La tercera contingencia se integra a través de la dimensión temporal añadida del futuro y, con ello, mediante la referencia a los futuros afectados. Esta perspectiva tiene como consecuencia la necesidad de considerar, junto a las consecuencias imprevisibles en el presente, la contingencia de los sujetos que interpretan y actúan en el futuro. De esta manera, queda incierto cómo y qué generaciones futuras aplicarán y valorarán el legado de las generaciones presentes. Con que en este punto hay que contar con la discontinuidad.

Por otro lado, es importante relativizar el principio de apertura de la historia; puesto que el principio de la libertad de elección no debe absolutizarse. Cada libre elección tiene lugar únicamente dentro de las condiciones históricas bajo las cuales puede ser elegida. Tales condiciones limitan el horizonte de posibilidades, al igual que, al mismo tiempo, se necesitan determinadas condiciones para aumentar el radio de acción. De ahí se deriva la tarea de formular un modelo alternativo de apertura de los procesos históricos. Esto concierne, por una parte, al principio de libertad de elección y, por otra parte, a la realización práctica.

No hay que confundir la libertad de elección con arbitrariedad. Podría así malentenderse que el futuro se encuentra tan "abierto" que las comprobaciones no serían posibles o deseables. Por el contrario, se puede impedir, bajo

14 Luhmann (1984), 154 y ss. 
determinadas circunstancias, limitar ciertas posibilidades de elección. A éstas pertenecen, por ejemplo, la elección ficticia de que los humanos de épocas futuras renunciarán a la naturaleza y se sentirán más a gusto en espacios climatizados. Tampoco sería una objeción convincente aquella según la cual no se puede o debe excluir que también los seres humanos que vivan en el futuro apreciarían una naturaleza intacta. Es más importante que nos ocupemos de que la protección de la naturaleza continúe siendo un valor y evitar así tener que plantearnos absurdas alternativas de este tipo.

De la circunstancia de que cada posibilidad de elección depende de las condiciones bajo las cuales pueden ser elegidas se sigue que es necesario crear las relaciones correspondientes que garanticen poder elegir la mayor cantidad de opciones posibles. De ahí resulta, sin embargo, que otras condiciones concretas, que contienen peligros e impiden la realización de determinadas necesidades e intereses deben ser excluidas. Únicamente bajo este presupuesto se puede proteger el margen de opciones o bien cambiarlo de tal modo que las mejoras también sean posibles. En relación a la apertura, es necesaria igualmente la exclusión de riesgos. Por estas razones, sostengo que una apertura condicionada es apropiada.

Este alegato es compatible con el postulado práctico de una continuidad en la historia que exija contenido a la contingencia absolutizada ${ }^{15}$. Aquí se exige ciertamente una acción alternativa que abandone los caminos seguros de una industrialización incondicionada; sin embargo, precisamente esta meta de un cambio económico y ecológico requiere de acuerdos vinculantes que tengan validez tanto a nivel nacional como global y durante un largo periodo ${ }^{16}$. Si, por ejemplo, los gobiernos se obligan a cumplir determinados objetivos sobre el cambio climático, esto perduraría siempre y cuando existan ciertas garantías a largo plazo. Por esta razón, la responsabilidad a largo plazo presupone continuidad

15 A diferencia del esbozo filosófico-transcendental de Baumgartner (1972); a este respecto: Zwenger (2008).

16 Un ejemplo clarificador para una continuidad de este tipo es la pregunta harto discutida sobre el derecho de autodeterminación que "tienen" los seres humanos que vivan en el futuro o si tienen derechos en absoluto. La respuesta bienintencionada de que hoy "atribuimos" determinados derechos a las personas que vivan en el futuro sigue siendo poco satisfactoria, si al mismo tiempo no se anticipa la continuidad histórica de una praxis social y cultural apropiada. - Baier (1980), 171 y ss.; Plechter (1980), 167 y ss.; Feinberg (1980), 170 y ss.; Warren (1980), 261 y ss.; De George (1980), 157 y ss.; Birnbacher (1988), 98 y ss.; Beckermann (2004), 4; Tremmel (2004), 6; Meyer (2005), 29 y ss.; Heubach (2008), 111 y ss.; Gesang (2011), 136. 
histórica, del mismo modo que sólo las prácticas continuamente repetidas posibilitan una responsabilidad como ésta.

\section{Plazos de la responsabilidad histórica}

En lo expuesto hasta el momento la historia se ha entendido como una secuencia diacrónica transmitida por herencia. De ahí surge la tarea de proporcionar las condiciones de posibilidad de un trato libre con el legado. Por eso, son necesarias ciertas medidas que puedan crear continuidades prácticas que lleguen hasta épocas futuras. Esto requiere de puentes diacrónicos que se lleven a cabo mediante la acción orientada al futuro. Esta exigencia es tanto más urgente cuanto que las posibilidades de intervención han aumentado drásticamente gracias a las nuevas tecnologías. Aquí se cuestiona hasta qué punto bastan las acciones humanas y en qué medida el ser humano puede hacerse responsable de ello. En el contexto de una ética que tenga en consideración no sólo un futuro "cercano", sino también uno "a medio plazo" y un futuro "lejano" ${ }^{17}$, se plantea el problema del alcance de la responsabilidad para con las generaciones futuras.

Pero no se trata únicamente de un tema ético, sino también de un tema propio de la filosofía de la historia; pues el lapso transcurrido entre las generaciones presentes y futuras no es un tiempo abstracto; ha de ser concebido, más bien, como un periodo histórico concreto que depende de las estructuras temporales y espaciales de los correspondientes ámbitos de acción. Aquí es necesario especificar la responsabilidad en el sentido de un futuro que sea comprendido como parte de la historia. Para esta diferenciación introduzco el concepto de plazo, concepto que, de nuevo, deduzco de la filosofía de la historia. Asimismo, extrapolo al futuro determinadas categorías de la teoría de la historia de corte fenomenológico.

Para especificar la dimensión histórica de futuras generaciones tomo distancia de dos posiciones contrarias. El universalismo ético sugiere la idea de postular una responsabilidad ilimitada para todos los seres humanos de todos los tiempos

${ }^{17}$ En la ética del futuro se ha establecido la diferenciación entre un pasado "cercano", "a medio plazo" y "lejano". Mientras que la ética tradicional se limita, desde esta perspectiva, a un futuro "cercano", la ética del futuro se ocupa, en sentido estricto, de espacios temporales "medios" y "largos", los cuales desde Hans Jonas se conoce como "nueva ética". - Jonas (1979), 215; Birnbacher (1988), 24 y ss., 156.; Birnbacher (2003), 81; Heubach (2008), 13 y ss., 134 y ss.; Veith (2006), 12, 153 y ss. 
y lugares ${ }^{18}$. Sin embargo, por muy justificado que pueda estar el postulado de la universalidad, no deja de ser cuestionable la consecuencia de que, en la responsabilidad vinculante, las distinciones temporales no debieran estar permitidas. Queda igualmente abstracta la limitación de esta responsabilidad a "media" distancia o al límite de las tres generaciones que viven simultáneamente ${ }^{19}$. Por tanto, la alternativa entre una responsabilidad temporal sin límites y una limitación general a un futuro cercano no es convincente.

Frente a estas dos posiciones contrarias, mi concepción consiste en graduar el alcance de la responsabilidad de una forma temporal y espacial. Si la ocasión para una dilatación temporal de la ética reside en la efectividad de la técnica moderna, entonces precisamente estos espacios de acción son decisivos para la graduación del futuro. De este modo, se puede limitar por completo la responsabilidad en cada caso particular para conceder las diversas exculpaciones tan deseadas. Al mismo tiempo, hay que ampliar decididamente los periodos, siempre que las consecuencias de la acción técnica, y de los peligros que ahí acechan, exijan una conducta adecuada. Esta propuesta complace, ciertamente, a aquellos que temen una exigencia moral excesiva del ser humano; sin embargo, no permite una delimitación absoluta de la responsabilidad moral.

El concepto de plazo, que tomo, a la vez que modifico, del ensayo de Günter Anders sobre filosofía de la historia Tiempo del fin y fin de los tiempos, se adecua a una diferenciación de este tipo ${ }^{20}$. Tras el final de la Guerra Fría no existe ya $e l$ plazo hasta que la catástrofe tenga lugar o pueda ser evitada, sino que, más bien, se muestran varios plazos. Surgen numerosos llamamientos o señales mortales (deadline en el sentido más propio del término) que no se deben sobrepasar. Después de que la historia fuera "despojada de todo plazo" durante la época de la ilustración ${ }^{21}$, existen nuevamente determinados vencimientos dentro de la historia.

18 Jonas (1979), 9, 89 y ss., 245. - Contra toda "refencia temporal" Rawls (1979), 319 y ss.; cf. Parfit (1976), 100 y ss.; del mismo autor (1981), 113 y ss.; Laslett (1992), 24 y ss.; Veith (2006), 127 y ss. - Para la "neutralidad temporal” véase Ekardt (2005), 59, 83; Veith (2006), 156.

19 Para la no caer en la "desfronterización de la responsabilidad" otros autores indican un "frontera" temporal de la responsabilidad: Gethmann (1993), 15; Birnbacher (2003), 82; Leist (2005), 4 y ss.; Sturma (2006), 221 y ss.

20 Günther Anders, Die atomare Bedrohung, Múnich, 1986, 170, 203.

${ }^{21}$ Blumenberg (1986), 180 y ss. 
Los plazos son ámbitos de acción dentro de los cuales hay que obtener determinados efectos de los que son responsables los seres humanos que actúan en el presente. De ahí se deriva cada plazo de acción, efecto y responsabilidad específico. Los plazos de la acción son aquellos plazos en los que hay que actuar para obtener o crear situaciones deseables para el futuro o bien para evitar daños. De los plazos de la acción resultan determinados plazos del efecto. Precisamente aquí hay que diferenciar a qué espacios temporales apuntan los efectos de las acciones que, una vez más, dependen, especialmente, del alcance temporal de la acción técnica. A la relación entre las acciones y sus consecuencias hacen referencia los plazos de la responsabilidad. Dado que los seres humanos temen o esperan provocar efectos, se hacen así responsables de ello. De ahí se deriva un horizonte factual, espacial y temporal: una persona o una institución es responsable de los sucesos en ciertos ámbitos y en determinados momentos en la medida que residan en el campo efectual de sus acciones. Bajo este presupuesto es posible variar la responsabilidad del futuro conforme a plazos.

Tal concepto de plazo es descriptivo y normativo al mismo tiempo. Primeramente, los plazos remiten a ciertos estados de cosas que se caracterizan por una determinada constelación de factores relevantes. Sus dimensiones temporales dependen de los alcances de las acciones humanas y de la predicción de las correspondientes consecuencias. En el transcurso de las repercusiones técnicas y económicas a largo plazo el futuro adquiere una estructura que se orienta a los contenidos de dominios factuales. Dependiendo del ámbito de los problemas, surgen diferentes plazos temporales y espaciales. Además, los plazos indican determinadas metas que deben alcanzarse mediante acciones dentro de periodos determinados. Puesto que los plazos hacen referencia a estados esperados, temidos y anhelados de los que determinados seres humanos o instituciones son responsables. Los plazos contienen una agenda que muestran qué hay que hacer en cada momento. Por eso, los plazos, así definidos, poseen una carga moral y una connotación ética.

En este contexto son apropiadas las categorías que el historiador y teórico de la historia Ferdinand Braudel ha desarrollado en conexión con la fenomenología de Husserl y de Henri Bergsons ${ }^{22}$. Al igual que respecto a la historia pasada se diferencia entre una "duración corta", "media" y "larga", del mismo modo se pueden pronosticar diferentes espacios temporales para el futuro, espacios que se

22 Ferdinand Braudel, Schriften zur Geschichte 1. Gesellschaften und Zeitstrukturen, Stuttgart, 1992, 49 y ss.; cf. Koselleck (2003), 287 y ss. 
ven perjudicados por los diversos ámbitos de acción con sus asuntos particulares correspondientes.

Los largos plazos son inducidos fundamentalmente mediante las prácticas tecnológicas y ecológicas. Aquí, el carácter a largo plazo no está vinculado tanto a las acciones precavidas, que se llevan a cabo en pocas décadas, como a las consecuencias de esas acciones, las cuales debido a su condicionamiento técnico se desarrollan a muy largo plazo. En este caso, somos también responsables cuando se encuentran en el futuro lejano. Aunque nosotros apenas si podemos imaginarnos a las personas afectadas y tan sólo podemos tomar precauciones de una forma indirecta, estamos obligados a mantener esta garantía. Los plazos extremadamente largos surgen, por ejemplo, con los residuos radioactivos: hay que mantenerlos alejados de la biosfera durante periodos casi inconmensurables ${ }^{23}$. En vista de esta duración, la generación de los próximos trescientos o incluso mil años es todavía relativamente real y concreta.

A pesar de la enorme distancia temporal, no cabe duda de que los seres humanos que viven en el presente son responsables de tales efectos a largo plazo. Esta responsabilidad se fundamenta no sólo en una ética universal que atribuya a los hombres de todo tiempo futuro el interés por la salud y, con ello, su derecho correspondiente, sino que, más bien, es indispensable aquí a causa del efecto real a largo plazo y del peligro que se prolonga en el tiempo a través de la tecnología nuclear. Si este riesgo puede ser eliminado o minimizado mediante la acción actual, existe una obligación concreta que va sin duda mucho más allá del límite de las tres generaciones o del alcance "medio" que se ha mencionado anteriormente. En este ámbito, una limitación general de la responsabilidad sería incluso sumamente negligente.

En la historiografía, los tiempos de "corta duración" hacen referencia a acontecimientos concretos, generalmente en el ámbito de las decisiones políticas. Esto es igualmente válido para los plazos cortos en el futuro. Si estos plazos afectan a los sistemas sociales, hablamos generalmente de crisis financieras, ante las cuales hay que actuar con la rapidez proporcional: en pocos meses, semanas, días o incluso horas. En tales casos, las personas que actúan son responsables de la generación

${ }^{23}$ Kornwachs (2000), 106; Böhler (2009), 44 y ss.; Leggewie, Welzer (2009), 11. La vida media radiactiva del plutonio 239 es de 24.390 años, del uranio 235 llega incluso hasta los 700 millones de años y del uranio enriquecido 238 para la producción de armas nucleares es 4.500 millones de años. 
afectada, tanto de la propia como de la siguiente (esto quiere decir de modo expreso que ya no se es responsable de las personas pertenecientes a generaciones posteriores). La obligación abstracta que va más allá de este límite temporal no posee aquí relevancia práctica alguna.

De forma similar, es lícito para los medios plazos que se determinen según los diferentes campos de acción, cuyos horizontes temporales, a los que les son inherentes tiempos históricos específicos, dependen de los sistemas naturales y sociales. En los periodos a medio plazo se trata, por ejemplo, del ámbito de los recursos naturales. Después de que las crisis del petróleo de 1973-74 y 1979-80 provocaran una última ola de descubrimientos y desarrollos, aproximadamente en nuestros días (unos 35 años más tarde) o en el futuro cercano se alcanzará el máximo de extracción de petróleo a nivel mundial. Con un consumo constante como el actual, las energías fósiles (sobre todo el petróleo) se habrán agotado en el 2050 o su aplicación será, cuanto menos, muy poco rentable ${ }^{24}$. A medio plazo son también los tiempos que aún están disponibles para impedir las consecuencias negativas del cambio climático, cuyos efectos se prolongarán en varios cientos de años ${ }^{25}$. Las acciones que se lleven a cabo en estos ámbitos durante las próximas dos décadas van a ser decisivas. Sin embargo, los plazos de responsabilidad y de efectos van más allá de las próximas dos décadas; puesto que, nosotros somos responsables precisamente para aquellas generaciones que serán afectadas por ello de forma inmediata. Por consiguiente, sobre este terreno es necesario extender claramente la responsabilidad moral más allá de las tres generaciones que viven simultáneamente.

Esta problemática se vuelve especialmente virulenta cuando los plazos hacen referencia no sólo al futuro, sino que remiten también al pasado ${ }^{26}$. Hay que observar aquí que determinados objetivos sobre el medio ambiente, estando orientados a un estadio temprano de la industrialización, poseen un lado prospectivo y otro

${ }^{24}$ Leggewie, Welzer (2009), 12.

${ }^{25}$ Los diversos escenarios que se tienen en cuenta para las diferentes cantidades de emisión dan como resultado un límite inferior (Untergrenze) de 1,1 grados en el aumento de la temperatura y un valor superior de 6,4 grados hasta finales de siglo. Para este periodo se estima que la subida del nivel del mar será de 18 a 59 centímetros, el mismo tiempo que dura el derretimiento de los glaciares en Groenlandia y en la Antártica. - Welzer (2008), 57; Leggewie, Welzer (2009), 27, 68 y ss., 167; Gesang (2011), 15 y ss.

26 Aquí no puedo profundizar en la problemática de hasta qué punto el hecho de causar (de forma involuntaria o incluso culpable) daños en el pasado debe ser compensado en el presente y el futuro. Cf. Rohbeck (2013), 92 y ss. 
retrospectivo. Si el regreso a estadios anteriores se muestra como una exigencia, se aúna con ello el deseo de reversiones.

Así, por ejemplo, los investigadores sobre el cambio climático exigen que, para mediados del siglo XXI, la expulsión de gases de efecto invernadero se reduzca al menos hasta la mitad del nivel de 1990. El año 1990 aparece una y otra vez, porque, desde entonces, la mayor parte de los Estados industriales tradicionales no han aumentado sus emisiones de forma considerable ${ }^{27}$. Otros ejemplos más realistas y que han tenido ya cierto éxito son los saneamientos de aguas contaminadas y la purificación del aire, la disminución de zonas desérticas en fase de expansión, la compensación de la erosión del suelo, la reforestación de bosques que han sido talados por completo y la recuperación de reservas pesqueras en los mares de todo el mundo. El objetivo es el restablecimiento en periodos temporales concretos de sistemas naturales, como por ejemplo el clima, o la regeneración de ecosistemas tales como las materias primas. La norma para el saneamiento se define de forma que deba restablecerse un estado anterior.

Este fenómeno remite al principio de reversibilidad. Esto no significa únicamente poder cancelar hoy en día determinadas tecnologías, sino, sobre todo, crear una tecnología que permita una autocorrección en el futuro.

Si se extrapola este principio a la totalidad de la historia, se origina una imagen cíclica de la historia ${ }^{28}$. Sin embargo, la absolutización del ciclo es irreconciliable con el saber moderno sobre la especificidad de los tiempos históricos. Igualmente problemática es la contraposición categórica entre ciclo natural y proceso de civilización. Puesto que, la naturaleza conoce no solamente ciclos, sino también procesos ascendentes como la cadena de las generaciones que se suceden en el tiempo. Por otra parte, en la historia se insertan determinados ciclos como la reproducción natural de los individuos y los procesos circulares en las instituciones sociales. Por eso, lo decisivo es integrar el principio de reversibilidad en el transcurso futuro de la historia.

27 Ott, Döring (2008), 336.

28 Conforme al concepto de "sostenibilidad estricta", el ciclo de la naturaleza y el proceso lineal y acelerado de la industrialización parecen excluirse mutuamente; Enge (2000), 68. - Más apropiado es el concepto "estructura de repetición” de Koselleck 2010, 96 y ss. 


\section{Justicia universal}

Los plazos poseen una dimensión espacial, así como una temporal. De ahí que haya que determinar con más precisión cuáles son las condiciones de vida que se deben crear, para qué generaciones, en qué lugares y en qué tiempos ${ }^{29}$. Pues no se puede negar que las crisis ecológicas o económicas pronosticadas tendrán efectos muy diferentes sobre pueblos concretos. Esto da como resultado un mapa histórico del futuro, sobre el cual aparecen marcadas las situaciones deseadas, críticas o amenazantes en determinados ámbitos. Si, por el contrario, incluimos el pasado, las situaciones señaladas serán susceptibles de ser comprendidas como consecuencia de los diferentes desarrollos, sin pasar por alto que los países menos desarrollados requieren de un apoyo especial.

Este fenómeno puede interpretarse con ayuda de una categoría que es propia de la filosofía de la historia: la simultaneidad de lo no simultáneo. Siguiendo a Ernst Bloch, la no simultaneidad de la que podemos hacer experiencia debe interpretarse no sólo como dilación, sino como posibilidad histórica frustrada, esto es, como no compensada y no consumada históricamente ${ }^{30}$. Ante estos procesos divergentes en el presente se plantea la tarea de la sincronización de lo no simultáneo. Ésta hace referencia a las divergencias ecológicas entre naturaleza y cultura, así como a la no simultaneidad global de la modernización entre los diferentes pueblos y culturas.

Aquí se plantea el problema de si los países menos desarrollados pueden exigir el derecho a "recuperar" un desarrollo que los países industrializados alcanzaron hace ya largo tiempo. Así, son objeto de discusión el controvertido concepto "proceso de recuperación del desarrollo" y el concepto modificado de "desarrollo sostenible"31. La concesión a esos países de un derecho al desarrollo conlleva el deber de igualar diferentes niveles. No es posible llevar a cabo una fundamentación de ese derecho sin remitirse a la Filosofía de la Historia. Voy a empezar

29 Hay que rechazar la tesis de una "globalización ecológica" que se refiera a "la humanidad" del mismo modo, Lienkamp 2009, p. 340, habla de un "igualitarismo de catástrofes" que ha de ser criticado.

30 Ernst Bloch, Das Prinzip Hoffnung, 3 Vols, Fráncfort del Meno. 1977, Vol. 4, 104 y ss.; en alusión a Walter Benjamin, Gesammelte Schriften, Fráncfort del Meno. 1974, Vol. I.2, 697 y ss.

31 Sobre este concepto de un modo ejemplar cf. Paehlke (1989), 113; Bartelmus (1994), 78 y ss.; Enge (2000), 9 y ss., 65 y ss.; Ekardt (2005), 29; Veith (2006), 167 y ss.; Grunwald, Kopfmüller (2006), 49 y ss.; Ott, Döring (2008), 41 y ss.; Böhler (2009), 16 f.; Heintel, Krainer (2010), 438 y ss. 
aclarando las implicaciones teóricas para intentar, posteriormente, presentar una fundamentación normativa.

La filosofia de la historia de la ilustración se ocupa de la "humanidad" como un individuo que progresa, desarrollando así su perfectibilidad ${ }^{32}$. Para esta tradición filosófica la historia universal significa que la decadencia de los pueblos individuales sirve para el progreso de la especie humana. Mientras los pueblos individuales se elevan y se hunden según el modelo de las edades de la vida humana, la humanidad en su conjunto no se ve afectada por ello, ya que ella se desarrolla de forma continuada. En el historicismo este proceso se representa de un modo totalmente diferente, rechazando la perspectiva universal de la historia y, en general, la idea de un desarrollo comparable a otros. De ahí se sigue que no se debería desvalorizar épocas anteriores que, desde una perspectiva actual, pudieran parecer menos avanzadas, pues cada pueblo y cada cultura tienen el mismo derecho a la felicidad ${ }^{33}$. Según esta variante, sería injusto que un pueblo se beneficiase del "progreso" mediante su participación en él, mientras otro quedara excluido. El concepto actual de proceso de recuperación del desarrollo se representa como una síntesis de estas formas de pensamiento histórico. Une la filosofía de la historia clásica con su perspectiva de progreso (pero sin un sujeto de la especie) y el historicismo con su horizonte nacional (pero sin la crítica radical de la cultura). Por lo tanto, cada pueblo tiene el derecho a participar en el proceso de la civilización global.

$\mathrm{Si}$, además, se busca una fundamentación normativa del derecho al desarrollo que se ha defendido, surge la siguiente pregunta: ¿se limita esta fundamentación a aplicar las reconocidas teorías de la justicia, acreditadas ya en nuestros días, a un futuro a corto, medio y largo plazo o hay normas específicas de la filosofia de la historia que pueden ser válidas en este contexto? Si es posible mostrar tales normas, entonces se puede llevar a cabo la pretensión de aportar una justificación propia del ámbito de la filosofía de la historia y que sea, al mismo tiempo, normativa.

La clásica filosofía de la historia se caracterizaba por estar esencialmente dirigida al futuro y, con ello, orientada a la acción. Su tarea consistía no sólo

32 De manera detallada Rohbeck (2010), 54 y ss.

33 Con Jonas remito a la máxima de que cada época "guarda una relación inmediata con Dios": Leopold von Ranke, Über die Epochen der neueren Geschichte, Múnich/Viena 1971, 59; sobre Ranke también Jonas (1979), 287. 
en reflexionar filosóficamente sobre sobre acontecimientos y procesos pasados, sino que, sobre todo, tenía la función de aportar la orientación para una praxis vinculada al futuro. De este modo, el concepto de progreso no se limitaba a la descripción de desarrollos, sino que contenía también la valoración positiva de los logros civilizatorios. Con ésta estaba unida la esperanza de progresos futuros y la exigencia moral de participar en la mejora de las condiciones de vida esperadas para el porvenir.

Por muy problemática que pueda parecer la idea de progreso en nuestros días, ya que, parcialmente, ha contribuido a desarrollos erróneos, el deseo de cuidar del bienestar de generaciones futuras y aspirar a mejores condiciones de vida en el futuro, o al menos procurar que no empeoren, continúa, sin embargo, estando de actualidad. Se trata aquí de una genuina norma de la filosofía de la historia que puede tener su validez también en nuestros días. Si se limita la expectativa de progresos a determinados sectores y se diferencia según espacio y tiempo, se puede evitar que se absolutice el concepto de progreso y que se lo exagere teleológicamente. En tal deseo de mejoras en el proceso histórico global se encuentra el núcleo de una fundamentación de la justicia universal a partir de la filosofía de la historia.

Este deseo contiene la conciencia histórica para que las condiciones de posibilidad de la acción humana se amplíen en la historia, abriendo así un nuevo horizonte de la civilización moderna ${ }^{34}$. Si se puede presuponer aquí algún interés, se deriva la intención práctica de no darse por satisfecho con estándares absolutos y mínimos ${ }^{35}$, tan pronto como se den los presupuestos para un aumento del nivel de vida ${ }^{36}$. Los seres humanos, en caso de que crean que es posible una mejora de sus circunstancias, pondrán de manifiesto esta exigencia y establecerán los requisitos correspondientes. Como habitantes de países menos desarrollados van a llevar a cabo esta exigencia, especialmente si reconocen como realidad concreta sus posibilidades reales apuntando a los países ricos. Un llamamiento adecuado

${ }^{34}$ Me baso aquí en la categoría de "posibilidad real” de Ernst Bloch, op. cit., vol. 1, 258 y ss., 278 y ss.; cf. Rohbeck (2000), 105 y ss.; del mismo autor (2013), 35 y ss.

35 Si se excluye una comparación histórica, esto conduce al concepto de "suficiencia" o "de "valor umbral"; Patridge (2002), 75 y ss.; Meyer (2005), 3, 23 y ss., 36 y ss.; cf. Ekardt (2005), 190; Heubach (2008), 116 y ss, 125; de manera crítica Gesang (2011), 52 y ss., 60 y ss., 136 y ss.

${ }^{36} \mathrm{Si}$ se hacen comparaciones históricas, se pueden diferenciar las posiciones siguientes. Primero: al menos tan grande, posiblemente también mejor; Pogge (2002), 143 y ss.; Tremmel (2012), 291; Ekardt 2005, 25 y ss.; Ott, Döring 2008, 101, 138 y ss.; Caney (2010), 203 y ss. Segundo: de un modo equivalente; Epstein (1992), 84 y ss.; Heubach (2008), 44. - Tercero: quizás también peor; Fishkin (1992), 62 y ss.; Sturma (2006), 230. 
está justificado siempre y cuando se pueda realizar bajo condiciones contingentes y se pueda incluir en un sistema coherente que proteja la naturaleza y respete la justicia social.

Un modelo de progreso modificado de tal modo tiene un significado triple. En primer lugar, para los paises pobres "progreso" significa, nada más y nada menos, que un estándar mínimo para alcanzar sus condiciones de vida bajo las cuales pueden satisfacer sus necesidades básicas ${ }^{37}$. Sin embargo, los países industrializados, por su parte, no tienen una pretensión ilimitada de "progreso". Incluso están obligados a renunciar a él hasta que los países emergentes y en vías de desarrollo no hayan alcanzado sus desarrollos esenciales y deseados. En este caso se aplican los modelos de historia del estancamiento o incluso de la decadencia en el sentido de una bajada controlada. Finalmente, no hay que confundir el alegato en favor de los "progresos" en los países menos desarrollados con un optimismo ingenuo, porque, con ello, lo que se intenta es plantear desarrollos alternativos. Precisamente para los países desfavorecidos se abre la posibilidad de tomar otro camino de modernización.

\section{5. ¿Para qué filosofía de la historia?}

Para terminar se plantea una vez más la pregunta por la función de la filosofía de la historia en los discursos sobre la responsabilidad para con las generaciones futuras. Ahí quedó de manifiesto que términos como "país en vía de desarrollo" o "país emergente", así como el concepto "proceso de recuperación del desarrollo" tienen un sentido que es característico de la filosofía de la historia. El concepto de desarrollo ahí contenido presupone, por otro lado, los teoremas de la "simultaneidad de lo no simultáneo" y la "sincronización de lo no simultáneo". Para concebir la historia como un proceso condicionadamente abierto hay establecer una nueva relación entre las categorías "contingencia histórica" y "continuidad práctica". Se podría probar que conceptos elementares como "generación” y "legado", como también "futuro" y "plazo" proceden originariamente de la filosofía de la historia.

\footnotetext{
37 Mientras que el planteamiento de las "necesidades básicas" hace referencia fundamentalmente a los aspectos materiales, el concepto de "oportunidades de realización" apunta a la suma de las capacidades de satisfacer las propias necesidades y vivir una vida autodeterminada. - Sen (2009), 231, 271; Nussbaum (2001), 87 y ss.; cf. Weikard (1999), 163 y ss.; Ott, Döring (2008), 83 y ss. - Además, el debate sobre el igualitarismo ha demostrado que la exigencia de estándares absolutos y de estándares comparativos aproximadamente iguales conducen de hecho al mismo lugar. Cf. Krebs (2001), 157 y ss.; Ott, Döring (2008), 78 y ss.; Gesang (2011), 48 y ss., 93 y ss.
} 
Esto también es aplicable a la norma específica propia de la filosofía de la historia de un deseo de mejoras.

Por lo que respecta a estos conceptos, teoremas e imágenes de la historia, se trata generalmente de modelos de interpretación de lo histórico. Estos modelos los entiendo, de manera muy general, como representaciones en las que se condensan experiencias solidificadas, disposiciones subjetivas, valores y normas, concepciones del mundo o esbozos de sentido. Pero si la historia (Geschichte) puede ser considerada como aquel ámbito que es "creado" por los hombres bajo determinadas circunstancias, entonces se trata, en el fondo, de autointerpretaciones de la propia Historia (Historie). Decisivo en nuestro contexto es que estos modelos de interpretación sirven no únicamente para la presentación y valoración de la historia pasada y las situaciones presentes, sino que, además de eso, en las discusiones sobre el futuro juegan un papel que no se debe minusvalorar.

Los discursos sobre el futuro describen un espacio histórico de acción que no se debe dar en absoluto por cerrado, sino que está aún por transitar y configurar. De este modo son parte de la planificación de acciones, e incluso, en última instancia, elementos de las acciones mismas. Estas representaciones de lo real posible son históricas no sólo por su carácter colectivo y a largo plazo; el carácter histórico específico surge además de la creación de modelos de interpretación en la reflexión sobre los desarrollos contemporáneos con referencia a nuestros valores actuales que en el presente tienen el efecto de orientación hacia la acción, determinando así el modo en el que influimos en el futuro dentro del marco de nuestras posibilidades.

La imagen del ciclo natural en el concepto de la sostenibilidad apela, por ejemplo, a conservar el medio natural. Asimismo, la imagen de la historia de la estancación exige detener el proceso de industrialización para proteger la naturaleza y conservar la cultura existente. Mientras que en la filosofía de la historia de la ilustración la interrupción o el retroceso fueron valorados de forma negativa, bajo las actuales condiciones es conveniente llevar a cabo una reinterpretación parcial para poder así revalorizarla. En cambio, la idea de progreso alienta a no abandonar la esperanza de que, al menos, se pudieran mejorar las condiciones de vida de los desfavorecidos hasta el momento y que, precisamente mediante progresos técnicos, pudieran hacer retroceder la destrucción de la naturaleza.

Bajo estos presupuestos no sostengo únicamente que una relación cargada de reflexión con los modelos de interpretación de lo histórico está justificada, sino 
que es indispensable; pues se ha mostrado qué potenciales descriptivos y normativos se pueden desarrollar en las discusiones sobre el futuro. Siempre y cuando estos potenciales se usen en debates políticos, se podrá hablar de una politica de la historia. De este modo contribuyen a una re-politización del futuro. Aquí veo la oportunidad de que la filosofía de la historia aborde el futuro como un campo de acción de historias posibles y, al mismo tiempo, desarrolle, en conexión con la ética del futuro, medidas éticas para una acción orientada al futuro y consciente de su responsabilidad. 


\section{Bibliografía}

Baier, Annette (1980), “The Rights of Past and Future Persons", en: Ernest Patridge (ed.), Responsibilities to Future Generations. Environmental Ethics, Nueva York, 171 183.

Bartelmus, Peter (1994), Environment, Growth and Development. The Concepts and Strategies of Sustainability, Londres.

Baumgartner, Hans Michael (1973), Kontinuität und Geschichte, Fráncfort del Meno 1972

- (1996), Philosophie der Geschichte nach dem Ende der Geschichtsphilosophie, in: Herta Nagl-Docekal (ed.), Der Sinn des Historischen, Fráncfort del Meno.

BeCKerman, Wilfred (2004), "Intergenerational Justice”, en: Intergenerational Justice Review, 2, 1-5.

BirnbaCHER, Dieter (1988), Verantwortung für zukünftige Generationen, Stuttgart.

- (2003), "Verantwortung für zukünftige Generation - Reichweite und Grenzen”, en: Stiftung für die Rechte zukünftiger Generationen (ed.), Handbuch Generationengerechtigkeit, Múnich, 81-103.

- (2008), "Langzeitverantwortung - das Problem der Motivation", en: Carl Friedrich Gethmann und Jürgen Mittelstraß (eds.), Langzeitverantwortung. Ethik - TechnikÖkologie, Darmstadt, 23-39.

Blumenberg, Hans (1986), Lebenszeit und Weltzeit, Fráncfort del Meno.

Bartelmus, Peter (1994), Environment, Growth and Development, Londres.

BöHLER, Dietrich (2009), Zukunftsverantwortung in globaler Perspektive, Bad Homburg.

Bourdieu, Pierre (1983), "Ökonomisches Kapital, kulturelles Kapital, soziales Kapital”, en: Soziale Ungleichheiten, editado por Reinhard Kreckel, Gotinga, 183-198

Caney, Simon (2010), "Climate Change and the Duties of the Advantaged", en: Critical Review of International Social and Political Philosophy 13, 1, 203-228.

De George, Richard T. (1980), “The Environment, Rights, and Future Generations”, en: Ernest Patridge (ed.), Responsibilities to Future Generations. Environmental Ethics, Nueva York, 157-165

Ekardt, Felix (2005), Das Prinzip Nachhaltigkeit. Generationengerechtigkeit und globale Gerechtigkeit, Múnich.

Enge, Kristin (2000), Zeit und Nachhaltigkeit, Berlín. 
Epstein, Richard A. (1992), "Justice across the Generations", en: Peter Laslett und James S. Fishkin (eds.), Justice between Age Groups and Generations, New Haven / Londres, 84-106.

FeinberG, Joel (1980), "Die Rechte der Tiere und zukünftigen Generationen“, en: Dieter Birnbacher (ed.), Ökologie und Ethik, Stuttgart, 140-179.

Fishkin, James S. (1992), “The Limits of Intergeneral Justice”, en: Peter Laslett / James S. Fishkin (eds.), Justice between Age Groups and Generations, New Haven/ Londres, 62-83.

Gesang, Bernward (2011), Klimaethik, Fráncfort del Meno.

Gethmann, Carl Friedrich (1993), "Langzeitverantwortung als ethisches Problem im Umweltstaat", en: Langzeitverantwortung im Umweltstaat, Bonn, 1-21.

Grunwald, Armin / Kopfmüller, Jürgen (2006), Nachhaltigkeit, Fráncfort del Meno.

Hauff, Volker (ed., 1987): Unsere gemeinsame Zukunft. Der Brundtland-Bericht der Weltkommission für Umwelt und Entwicklung, Greven.

Heintel, Peter / Krainer, Larissa (2010), "Geschichtlich-kulturelle Nachhaltigkeit", en: Erwägen Wissen Ethik, año. 21, número 4, 435-446.

Heubach, Andrea (2008), Generationengerechtigkeit-Herausforderung für die zeitgenössische Ethik, Gotinga.

Höffe, Otfried (1993), Moral als Preis der Moderne, Fráncfort del Meno.

HöLscher, Lucian (1999), Die Entdeckung der Zukunft, Fráncfort del Meno.

Jonas, Hans (1979), Das Prinzip Verantwortung, Fráncfort del Meno.

Kopfmüller, Jürgen / Brandl, Volker / Jörissen, Juliane / Paetau, Michael / Banse, Gerhard / Coenen, Reinhard und Grunwald, Armin (eds., 2001), Nachhaltige Entwicklung integrativ betrachtet, Berlín.

KornwaChs, Klaus (2000), Das Prinzip der Bedingungserhaltung, Münster.

Koselleck, Reinhart (1979), Vergangene Zukunft, Fráncfort del Meno.

- (2003), Zeitschichten. Studien zur Historik, Fráncfort del Meno.

- (2010), Vom Sinn und Unsinn der Geschichte, Fráncfort del Meno.

Krebs, Angelika (2001), "Wieviel Natur schulden wir der Zukunft?", en: Dieter Birnbacher und Gerd Brudermüller (eds.), Zukunftsverantwortung und Generationensolidarität, Würzburg, 157-182.

LAslett, Peter (1992), "Is There a Generational Contract?", en: Peter Laslett / James S. Fishkin (eds.), Justice between Age Groups and Generations, New Haven / Londres, 24-47. 
Leggewie, Klaus / Welzer, Harald (2009), Das Ende der Welt, wie wir sie kannten, Fráncfort del Meno.

LeIsT, Anton (2005), “Ökologische Gerechtigkeit”, en: Julian Nida-Rümelin (ed.), Angewandte Ethik. Die Bereichsethiken und ihre theoretische Fundierung. Ein Handbuch, Stuttgart, 426-513.

Lienkamp, Andreas (2009), Klimawandel und Gerechtigkeit, Paderborn.

Lüвве, Hermann (1993), Geschichtsphilosophie. Verbliebene Funktionen, Erlangen / Jena.

Luhmann, Niklas (1984), Soziale Systeme, Fráncfort del Meno.

Marquard, Odo (1973), Schwierigkeiten mit der Geschichtsphilosophie, Fráncfort del Meno.

Meyer, Lukas H. (2005), Historische Gerechtigkeit, Berlín / Nueva York.

Nagl-Docekal, Herta (1996), "Ist Geschichtsphilosophie heute noch möglich?”, en:

Nagl-Docekal, Herta (ed.), Der Sinn des Historischen, Fráncfort del Meno, 7-63.

Nussbaum, Martha Craven (2001), Women and human development, Cambridge / New York / Melbourne.

Oтт, Konrad / Döring, Ralf (2008), Theorie und Praxis starker Nachhaltigkeit, Marburg.

Paehlke, Robert C. (1989), Environmentalism and the Future of Progressive Politics, New Haven / Londres.

PArfit, Derek (1976), "On Doing the Best for Our Children”, en: Michael Bayles (ed.), Ethics and Population, Cambridge (Massachusetts), 100-112.

Parfit, Derek (1981), "Future Generations: Further Problems", en: Philosophy \& Public Affairs 11, 2, 113-172.

Partridge, Ernest (2002), “The Future - For Better or Worse”, en: Environmental Values, 11 1, 75-85.

Plechter, Galen K. (1980), “The Rights of Future Generations”, en: Ernest Patridge (ed.), Responsibilities to Future Generations. Environmental Ethics, Nueva York, 167-179.

Pogge, Thomas W. (2002), World Poverty and Human Rights, Malden (Massachusetts).

Putnam, Robert D. (ed., 2001): Gesellschaft und Gemeinsinn, Gütersloh.

Rawls, John (1979), Eine Theorie der Gerechtigkeit, Fráncfort del Meno.

Rohbecк, Johannes (2000), Technik - Kultur - Geschichte, Fráncfort del Meno.

- (2010), Aufklärung und Geschichte, Berlín.

- (2013), Zukunft der Geschichte. Geschichtsphilosophie und Zukunftsethik, Berlín. 
RüsEN, Jörn (1994), Historische Orientierung, Colonia / Weimar / Berlín.

SEn, Amartya (2009), The idea of justice, Londres / Nueva York / Ontario.

Sturma, Dieter (2006), "Die Gegenwart der Langzeitverantwortung”, en: Claus Langbehn (ed.), Recht, Gerechtigkeit und Freiheit, Paderborn, 221-238.

Thomson, David (1992): "Generations, Justice, and the Future of Collective Action", en: Peter Laslett / James S. Fishkin (eds.), Justice between Age Groups and Generations, New Haven / Londres, 237-235.

Tremmel, Jörg (2004), “Is a Theory of Intergenerational Justice Possible?”, en: Intergenerational Justice Review 2, 6-9.

(2012), Eine Theorie der Generationengerechtigkeit, Münster.

UnNerstall, Herwig (1999), Rechte zukünftiger Generationen, Wurzburgo.

VeITH, Werner (2006), Intergenerationelle Gerechtigkeit, Stuttgart.

Warren, Mary Anne (1980): “Do Potential Persons Have Rights?”, en: Ernest Patridge (ed.), Responsibilities to Future Generations. Environmental Ethics, Nueva York, 261273.

WEIKARD, Hans-Peter (1999), Wahlfreiheit für zukünftige Generationen, Marburgo.

Welzer, Harald (2008), Klimakriege. Wofür im 21. Jahrhundert getötet wird, Fráncfort del Meno.

Zwenger, Thomas (2008), Geschichtsphilosophie. Eine kritische Grundlegung, Darmstadt.

Recibido: 26/11/2014

Aceptado: 18/05/2015

Este trabajo se encuentra bajo una licencia de Creative Commons ReconocimientoNoComercial-SinObraDerivada 4.0

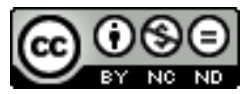

